\title{
EL ENFOQUE INSTITUCIONAL: UN PARADIGMA PARA LA ECONOMÍA PERUANA
}

Mg. Vladimir Rodríguez Cairo*

\begin{abstract}
RESUMEN
Douglass North -Premio Nobel de Economía en 1993- analizó el papel que cumplen las instituciones en el crecimiento económico. Una economía sin sistemas institucionales administrativos capaces de manejar adecuadamente los programas de desarrollo económico difícilmente aseguran el crecimiento económico. Las economías subdesarrolladas como la nuestra no cuentan con sistemas institucionales eficaces.

En ese entender, el Enfoque Institucional o Nueva Economía Institucional incorpora la Teoría de las Instituciones a la Teoría Económica. Enfatiza que la estructura de incentivos de la sociedad -que es fundamental para el proceso de cambio- es una función de la estructura institucional de la sociedad.

En ese sentido, el presente artículo sostiene la necesidad impostergable del fortalecimiento institucional en nuestro país para manejar adecuadamente los programas de desarrollo y asegurar el crecimiento económico sostenido. Se presenta el marco teórico y conceptual de las instituciones y organizaciones, la importancia de los derechos de propiedad, un breve análisis de la debilidad institucional y el fortalecimiento institucional, concluyendo con las ideas más importantes de este enfoque.
\end{abstract}

\section{INTRODUCCIÓN}

Si se intenta establecer los principales factores que han contribuido con el crecimiento económico de los países desarrollados no sólo se debe considerar la estabilidad de las principales variables: moneda y tipo de cambio, la liberalización de los mercados (financieros, cambiarios, de capitales, etc.), el libre comercio e integración con el mundo, la libre movilidad de los factores de la producción, la promoción e incentivo a la inversión privada tanto nacional como extranjera, el equilibrio fiscal (finanzas públicas sanas), la conveniencia de privatizar las empresas públicas, los subsidios mínimos, la no protección de industrias ineficientes, un mínimo de trámites burocráticos para incorporar los negocios a la legalidad, los bajos impuestos, los derechos de propiedad claramente establecidos, la creación de organismos reguladores para velar por la sana competencia, transparencia y eficiencia del mercado; sino también se debe considerar aquellos factores destinados al fortalecimiento institucional (reglas de juego claras), esto es, que se garantice los derechos de propiedad (no sólo es suficiente establecer los derechos de propiedad, debe prevalecer el cumplimiento de los contratos y la no expropiación), un

- Docente Auxiliar de la Facultad de Ciencias Contables. 
sistema que limite el poder de los gobiernos de turno, la reforma de la administración de justicia, la reforma de la capacidad de fiscalización del Poder Legislativo, la reforma educativa, la estabilidad política, entre otros.

\section{Instituciones y Organizaciones}

Según el profesor North, las instituciones son las reglas de juego de una sociedad; se entiende por sociedad a la organización en la cual el intercambio y la producción no sólo están mediados por los mercados sino por una serie de arreglos formales e informales. En otras palabras, las instituciones son las restricciones inventadas por los seres humanos para estructurar las interacciones entre los individuos. Estas restricciones, conocidas por la Nueva Economía Institucional como instituciones, reducen la incertidumbre por el hecho de que proporcionan una estructura a la vida diaria. Las instituciones se componen de:

1) Reglas formales o restricciones formales (constituciones, leyes, derecho consuetudinario, regulaciones y demás dispositivos legales).

2) Reglas informales o restricciones informales (convenciones, normas de comportamiento o normas sociales, códigos de conducta autoimpuestos, prácticas burocráticas).

3) La imposición de ambos (mientras las reglas formales pueden cambiar de la noche a la mañana como resultado de decisiones políticas o judiciales, las restricciones informales incorporadas en las costumbres, las tradiciones y las restricciones culturales cambian gradualmente, ya que no sólo conectan el pasado con el presente y el futuro, sino que nos proveen un mecanismo para explicar la trayectoria del cambio histórico).
En realidad, contamos con información incompleta y capacidad mental limitada para procesar la información. La información incompleta así como la capacidad mental limitada para procesar la información determinan los costos de transacción, los cuales constituyen la base para la formación de las instituciones.

Los costos de transacción son aquéllos en que toda persona o empresa incurre para informarse, negociar, contratar y hacer cumplir las condiciones de cualquier transacción o intercambio. Por ejemplo, una persona que compra un inmueble incurre en diversos costos de transacción; deberá pagar a una inmobiliaria para que ayude a ubicar el mejor lugar y a un abogado para que verifique que el vendedor realmente es el dueño de la propiedad puesta en venta; asimismo, para asegurarse de que el inmueble le sea transferido legalmente deberá acudir ante una notaría y a los registros públicos. Estos costos se realizan con la finalidad de tener seguridad jurídica. Los costos de transacción surgen debido a que la información es costosa y se retiene de manera asimétrica (desigual) por la parte que realizan el intercambio. Los costos de transacción pueden ser:

1) Costos de búsqueda o medición de bienes y/o servicios intercambiados (adquirir información).

2) Costos de hacer valer o cumplir los derechos de propiedad (exigibilidad de las reglas). En economía, los costos de transacción disminuyen la eficiencia de las relaciones de intercambio o transacciones.

Las instituciones son las reglas de juego que permiten que los costos de transacción se reduzcan y en consecuencia que el intercambio sea viable. La principal función de las instituciones (económicas, políticas, 
sociales, culturales), sean éstas formales (definidas por el mandato de la Ley) o informales (definidas por las normas o convenciones sociales) es reducir la incertidumbre en el intercambio humano a través del establecimiento $y$ fortalecimiento de reglas de juego claras, las cuales son necesarias para darle estabilidad al sistema económico.

Las leyes son las que dan la legitimación esencial a todo marco de reglas formales. Sin embargo, aquellas sociedades que adoptan reglas formales de otra sociedad (como es el caso de nuestro país) tendrán características de funcionamiento muy diferentes a la del país original debido a que tanto las reglas informales como las características de imposición serán distintas. Por lo tanto, la adopción de reglas formales no constituye una condición suficiente para el buen funcionamiento y resultado económico exitoso. Son los poderes del Estado (Ejecutivo, Legislativo y Judicial) los que determinan el funcionamiento económico porque son ellos los que definen e imponen las reglas de juego económicas. Por esta razón el objetivo fundamental de la política de desarrollo de un país debe consistir en la creación de un Estado que establezca e imponga derechos de propiedad eficientes.

La existencia de instituciones que aseguran los derechos de propiedad privada, así como la exigibilidad de los contratos son factores determinantes para la eficiencia de los mercados.

En ese entender, los sistemas económicos -capitalistas o socialistasson arreglos históricamente constituidos que conciernen a la totalidad de una sociedad, a partir de los cuales los agentes económicos como las familias, empresas y gobierno emplean recursos (naturales, humanos, capital, tecnología y capacidad empresarial) e interactúan en el proceso económico por la vía de la producción, la distribución y el uso de los productos, generados dentro de mecanismos institucionales de control que caracterizan la organización económica.

Las organizaciones son grupos de personas unidas en torno a un propósito común para alcanzar determinados objetivos. Dichas organizaciones incluyen organismos políticos (partidos políticos, municipalidades, poderes del Estado, entidades regulatorias), organismos económicos (empresas, sindicatos, cooperativas), organismos sociales (iglesias, clubes, asociaciones deportivas) y organismos educacionales (escuelas, institutos superiores, universidades, centros de formación profesional). Son los llamados agentes del cambio institucional.

Las instituciones políticas pueden ser estables sólo si cuentan con el apoyo de organizaciones que tienen interés en perpetuarlas. Por ello, un aspecto fundamental de las reformas políticas y económicas es la creación de tales organizaciones.

Ronald H. Coase -Premio Nobel de Economía en 1991- considera muy importante el sistema legal en el mundo moderno; descubrió y aclaró la importancia de los costos de transacción y de los derechos de propiedad para el funcionamiento de la economía; específicamente sostiene que los derechos económicos son fundamentales para la estructura institucional y el funcionamiento de la economía.

El planteamiento de Coase abrió el campo del Derecho y la Economía; ha permitido el surgimiento de una nueva rama de estudio: el Derecho Económico; el mismo que se concibe como las reglas de juego que rigen el sistema económico. Como es de entender, lo que se intercambia en el mercado no son únicamente bienes físicos sino también 
derechos que las personas tienen sobre diversos activos establecidos en el sistema legal. Los derechos de propiedad legal son el medio a través del cual el Estado asigna derechos económicos.

Hernando De Soto, en El Misterio del Capital sostiene que: «Es preciso entender un punto crucial: la propiedad no es algo físico... La propiedad no es una cualidad primaria de los activos sino la expresión legal de un consenso económicamente significativo acerca de ellos. La Ley es el instrumento que fija y realiza el capital... La propiedad no consiste en los activos mismos sino en el consenso entre personas respecto de cómo éstos deben ser poseídos, utilizados e intercambiados».

Consecuentemente, estudiar cómo las organizaciones económicas, políticas, sociales, educacionales impulsan el cambio y el fortalecimiento institucional exige una interacción de la ciencia económica con las demás ciencias sociales.

\section{Importancia de los Derechos de Propiedad}

Los derechos de propiedad son títulos legales que rigen y amparan la propiedad, el uso y el destino de los recursos; tienen la característica esencial que pueden hacerse valer ante los tribunales. Los derechos de propiedad son normas legales que describen lo que pueden hacer las personas o empresas con su propiedad.

Shahid Yusuf y Joseph E. Stiglitz sostienen que los derechos de propiedad que son protegidos y exigibles son el alma de una eficiente economía de libre mercado. Al fortalecer la confianza de los inversionistas los derechos de propiedad movilizan o impulsan los flujos de capitales hacia diversas actividades productivas y específi- camente fomentan el crecimiento económico.

La protección de los derechos de propiedad también incrementa la inversión extranjera directa y a través de ella el volumen del comercio, así como de las transferencias de tecnología.

Los países en vías de desarrollo como el nuestro se caracterizan por no haber explotado completamente todo su potencial de crecimiento debido a las débiles instituciones que protegen los contratos y derechos. Muchos derechos de propiedad están definidos de manera informal y débilmente exigibles ante la Ley; esta situación restringe la inversión privada.

La experiencia de diversos países ha demostrado que los derechos formalmente definidos y que gozan de la sanción de la ley son mucho más útiles para el crecimiento económico que las reglas informales avaladas por la costumbre y puestos en vigor a través de la comunidad o mediante mecanismos extralegales.

Por lo tanto, se requiere que los derechos de propiedad estén claramente definidos y que se establezcan mecanismos legales que los protejan. Esto involucra replantear el papel del Estado respecto al sector privado y de su capacidad legal. Sin embargo, los derechos no pueden ser protegidos sin el apoyo de los recursos públicos.

\section{La Economía Peruana y la debilidad institucional}

Con el propósito de establecer esta relación, se plantean las interrogantes siguientes:

¿En nuestro país la debilidad institucional $o$ inexistencia de reglas de juego claras atentan contra el funcionamiento de los programas de 
desarrollo económico? Y ¿Por qué las reglas de juego de la sociedad peruana $y$ el respeto a los derechos de propiedad privada son débiles o inexistentes?

En primer lugar, se puede afirmar que nuestra economía se encuentra estable en términos macroeconómicos (moneda y tipo de cambio); asimismo, la recaudación tributaria sigue fortaleciéndose y resulta imprescindible preservar la autonomía del Banco Central de Reserva para continuar con una política monetaria cauta. También hace falta continuar con la reestructuración del tamaño del Estado sin que se vean afectados los servicios que brinda y la reforma del gasto público para lograr el equilibrio fiscal. Con relación a la supremacía de la Ley, aún resulta ineficaz lo que se ha avanzado contra la corrupción, la misma que se caracteriza por debilitar la democracia y destruir la legitimidad de las instituciones y los gobiernos de turno.

En segundo lugar, si bien es cierto que se han cumplido algunos de los objetivos de la política económica, como son la estabilidad de precios y el relativo crecimiento económico; sin embargo, el actual modelo económico precisa de correcciones o variaciones porque aún no ha resuelto los grandes problemas de nuestro país que son la extrema pobreza y el deficiente marco institucional, los cuales limitan el crecimiento económico sostenido del país. Una economía sin sistemas institucionales administrativos capaces de manejar adecuadamente los programas de desarrollo económico, difícilmente aseguran el crecimiento económico. Las economías como la nuestra no cuentan con sistemas institucionales eficaces. El Estado peruano se caracteriza por ser un Estado débil (los esfuerzos realizados hasta ahora no son los más eficaces) y como es de entender, la debilidad institucional es un obstáculo para cualquier intento de crecimiento económico sostenido.

\section{El Fortalecimiento Institucional}

Por lo expresado anteriormente, nuestro país precisa del fortalecimiento institucional, especialmente de la existencia de instituciones que aseguren los derechos de propiedad legal y de mecanismos legales que los protejan. Asimismo, hace falta que se garantice la supremacía o imperio de la Ley, un marco legal que limite constitucionalmente el poder de los gobiernos de turno, la reforma de la administración de justicia (sistema judicial independiente y eficaz), la reforma de la capacidad de fiscalización del Poder Legislativo y la reforma educativa (las instituciones educativas son los caminos de bienestar y libertades personales). Todo esto se requiere del gobierno; sin embargo, es importante tener en cuenta que un gobierno muy opresivo no es la única razón que imposibilita los mercados; generalmente, el problema radica en un gobierno demasiado débil.

La Constitución Política debe crear y establecer un marco legal apropiado, para limitar los poderes del Estado, la protección de los derechos de la persona y la igualdad ante la Ley.

El Poder Legislativo debe mostrar, manifestar o demostrar fundamentalmente autonomía, modernidad y capacidad de fiscalización. Se requiere de un sistema que garantice la celeridad en la dación de las Leyes y la calidad de las mismas.

El Poder Ejecutivo no debe centralizar o concentrar el poder indebidamente, es necesaria una mayor democratización de las instituciones de nuestro país. El Ejecutivo no puede caer en tentaciones antidemocráticas ni populistas. 
El Poder Judicial debe ser totalmente autónomo frente a los otros poderes del Estado, también se necesita moralizar y despolitizar el sistema judicial.

En cuanto a los partidos políticos, la mayor competencia política vía elecciones primarias al interior del partido permitiría una renovación y modernización de los partidos. Es necesario democratizarlos. Es inconcebible e impracticable la democracia sin los partidos políticos. Para crecer económicamente debe existir estabilidad política por lo que se requiere la democratización, renovación y modernización de los partidos políticos.

Sin embargo, si los programas o planteamientos de la clase política no son correspondientes con las reformas económicas, sociales y con las expectativas de la población en general, los partidos políticos tienden a desaparecer o simplemente se convierten en un grupo de personalidades o partido de "personas notables".

Es importante señalar que el Estado de Derecho (Estado que se rige por normas constitucionales, que garantizan, reconocen y tutelan los derechos públicos subjetivados de los ciudadanos, mediante el sometimiento de la administración a la ley, tiene como principios fundamentales la supremacía de la ley, justicia independiente, rápida y eficaz, seguridad jurídica o específicamente protección de los derechos de propiedad, etc.), los derechos políticos (elecciones democráticas) y las libertades civiles (medios de comunicación libres e independientes, libertad de reunión y libertad de expresión) están correlacionados negativamente con la corrupción.

Milton y Rose Friedman, en Tiranny of the Status Quo, identifican tres tipos de tiranías:
1. Tiranía de los beneficiarios. Dentro de los cuales se encuentran:

1.1 Gremios laborales (sindicatos).

1.2 Gremios profesionales (colegios profesionales: de abogados, ingenieros, economistas, etc.).

1.3 Gremios empresariales o grupos monopólicos (lobby, lobistas). Buscan obtener rentas y privilegios del Estado o mantener las existentes. Ejercen presión sobre los legisladores y funcionarios del Estado (incluso los sobornan) con el objeto de que adopten decisiones en provecho de las organizaciones representadas (determinados proyectos de ley, colocación de pedidos estatales, subsidios).

2. Tiranía de los burócratas. Influencia excesiva de los funcionarios o empleados públicos en todas las actividades del Estado.

3. Tiranía de los políticos. Se caracterizan por desentenderse, luego de ser elegidos, del mandato que reciben.

Estos grupos presentan la mayor oposición al fortalecimiento institucional; constituyen lo que se ha denominado «El triángulo de hierro», por proteger los privilegios y derechos adquiridos. Milton y Rose Friedman sostienen que este grupo que conforman «El triángulo de hierro" es difícil de quebrantar por su propia naturaleza, fortaleza, consistencia y coincidencia de intereses.

\section{CONCLUSIONES}

1. Una de las causas fundamentales por las cuales las instituciones en nuestro país son ineficaces es la falta de 
competencia política. Se carece de un sistema político (conjunto de organismos políticos) que promueva el Estado de Derecho; el crecimiento a largo plazo requiere del desarrollo del Estado de Derecho. Los principios del Estado de Derecho son los siguientes: supremacía de la Ley (todos los agentes económicos que participan en la sociedad reconocen la necesidad de subordinar sus intereses al mandato de la Ley), igualdad ante la Ley (respeto por la Ley), seguridad jurídica (debe velarse por la estabilidad del sistema jurídico y la claridad de reglas de juego), supremacía de las personas (derechos de las personas), justicia independiente, rápida y eficaz (administración de justicia ordenada).

2. No se puede prescindir de un sistema jurídico estable y reglas de juego claras de la sociedad (importancia de las instituciones y organizaciones) donde deben operar los diversos agentes económicos. Requiere especial atención el respeto de los derechos de propiedad legal en oposición contra aquello que signifique su violación, como por ejemplo las expropiaciones, incumplimiento de contratos, etc.

3. La debilidad institucional o la no existencia de reglas de juego claras y su implicancia en el crecimiento económico puede conllevar a crisis económicas severas ya que la inversión de las empresas se vería considerablemente afectada en la medida que los derechos de propiedad legal sean inciertos o inconstantes, las leyes no se respeten o exista inseguridad jurídica, etc.

4. Para lograr una reforma institucional de éxito en nuestro país resulta imprescindible cambiar las institu- ciones y los esquemas de creencias y valores ya que son los modelos mentales de los agentes los que determinan las decisiones.

5. Finalmente, es necesario que el Estado cumpla su rol y haga prevalecer fundamentalmente la supremacía de la Ley, el respeto por ella y la seguridad jurídica. En nuestro país la piratería existe porque el riesgo de delinquir es relativamente bajo comparado con el beneficio obtenido. Si la matriz institucional recompensa la piratería, entonces aparecerán organizaciones piratas. Por ello es imprescindible una actitud coercitiva responsable por parte del Estado.

\section{BIBLIOGRAFÍA}

- BANCO MUNDIAL. Fronteras de la Economía del Desarrollo. El Futuro en Perspectiva. Alfaomega Grupo Editor S.A., Colombia, 2002.

- COASE Ronald. Essays on Economics and Economists. University of Chicago Press, 1994.

DE SOTO Hernando. El Misterio del Capital, Editora El Comercio S.A., Lima 2000.

FRANK Robert H. Microeconomía y Conducta. Editorial McGraw-Hill, España 1992.

- NORTH Douglass. Institutions, Institutional Change and Economic Performance. Cambridge University Press, 1990.

- PARKIN Michael. Economía. Sexta edición, Editorial Pearson Educación, México, 2004.

- $\quad$ PINDYCK RobertS. y RUBINFELD Daniel L. Microeconomía. Editorial Prentice Hall 2001.

- RODRÍGUEZ CAIRO Vladimir. Diccionario Bursátil Económico y Financiero. Impreso por IGMontero S.R.L., Lima, 1998. 